\title{
ESPECIALIZAÇÃO PRODUTIVA DA AGROPECUÁRIA EM DIFERENTES REGIÕES DO ESTADO DE SÃO PAULO: ENSAIO PARA IDENTIFICAÇÃO E CARACTERIZAÇÃO DE SISTEMAS LOCAIS DE PRODUÇÃO E INOVAÇÃO AGRÍCOLA ${ }^{1}$
}

Ricardo Firetti. APTA-SAASP, Polo Tecnológico Alta Sorocabana, Presidente Prudente-SP.

Éder Pinatti. APTA-SAASP, Instituto de Economia Agrícola, São Paulo-SP.

Maria Beatriz Machado Bonacelli. UNICAMP, Departamento de Política Científica e Tecnológica/Instituto de Geociências, Campinas-SP.

\section{RESUMO}

O artigo explora as características da agricultura paulista desenvolvida em diferentes regiões do Estado de São Paulo, compreendendo questões relacionadas à aglomeração da produção agrícola, singularidades e especialização regional. Tem por objetivo identificar aglomerações de produtos agrícolas relevantes em visão regional, sob a dimensão da quantidade produzida, visando subsidiar ações públicas de geração, adaptação e transferência de conhecimentos científicos e tecnológicos. Para tanto, foram calculadas a participação das regiões na produção estadual para 50 produtos utilizando variáveis de quantidades produzidas de diferentes regiões e do total do Estado de São Paulo. Os dados foram obtidos por meio de consulta a bases secundárias do IEA-APTA. Adicionalmente, foi utilizada a técnica de agrupamento multivariado two-way joining para visualização das aglomerações produtivas. Os resultados apontam a ocorrência de aglomerações importantes em regiões do estado, sinalizando grande especialização regional em determinados produtos tendo em vista a expressiva participação estadual. Pelo menos em 18 atividades, cerca de $72 \%$ da produção estadual está localizada numa das 15 regiões analisadas. Paralelamente, algumas regiões aparentam ser muito diversificadas por concentrarem a produção estadual diversos produtos agrícolas, tal qual o Sudoeste Paulista. Destaca-se o Centro Norte que concentra a produção de frutas tropicais no Estado

Palavras Chave: aglomeração; agrupamento; two-way-joinning

\begin{abstract}
The article explores the Sao Paulo State characteristics of agriculture developed in different regions, including issues related to the agglomeration of agricultural production, singularities and regional specialization. Aims to identify relevant agricultural products agglomerations regional vision in the size of the quantity produced, in order to support public share of the generation, adaptation and transfer of scientific and technological knowledge. Thus, we calculated the participation of the regions in state production to 51 products quantities produced using variables from different regions and the total of the Sao Paulo State. Data were, obtained, by consulting the secondary bases of the IEA-APTA. Additionally, we used the clustering technique multivariate two-way-joining for visualization of industrial agglomerations. The results indicate the occurrence of major conurbations in regions of the state, signaling major regional specialization in certain products with a view to significant state participation. At least 18 activities, about $72 \%$ of the state production is located in one of 15 regions analyzed. At the same time, some regions appear to be very diversified by focusing state production various agricultural products, like the Paulista West. Noteworthy is the North Center that concentrates the production of tropical fruits in the state.
\end{abstract}

Keywords: crowding; clustering; two-way-joining

ÁREA 1: Padrões de especialização produtiva e desenvolvimento

Classificação JEL: R12 - Size and Spatial Distributions of Regional Economic Activity

\footnotetext{
${ }^{1}$ Este trabalho integra pesquisa financiada pela FAPESP (Processo 2015/14310-7) intitulada "Embriões de sistemas locais de produção agrícola: mapeamento, caracterização e a interação entre as fontes de inovação”.
} 


\section{PROBLEMATIZAÇÃO}

Historicamente, a agricultura e pecuária tem elevada importância no Brasil, tanto em aspectos econômicos como sociais. Especificamente nos últimos 10 anos esse segmento do setor primário foi responsável, em média, por 6,3\% do Produto Interno Bruto (PIB) do país, segundo dados do CEPEA (2014). Em 2006 havia cerca de 4.920 .000 unidades de estabelecimentos na agropecuária, distribuídos entre proprietários, assentados, arrendatários, parceiros e ocupantes (IBGE, 2007), enquanto que a População Economicamente Ativa (PEA) no meio Rural correspondia a 18\% do total (IBGE, 2007b).

O agronegócio brasileiro foi responsável, em 2013, por 22,54\% do PIB total, crescendo 3,92\% em relação a 2012 com cifras de $\mathrm{R} \$ 1,092$ bilhões (CEPEA, 2014). Do total gerado pelo setor, a maior parcela, em torno de 31,7\% foi obtida pelo segmento de distribuição, enquanto $29 \%$ pelo segmento agropecuário, 28\% pela agroindústria e 11,7\% pelo segmento de insumos em geral.

Outro destaque favorável ao agronegócio é sua participação na balança comercial, representando 41,3\% do volume financeiro das exportações nacionais em 2013 e valores próximos a US\$100 bilhões (VICENTE, 2014). Os cinco principais grupos do agronegócio brasileiro nas exportações do ano de 2013 foram: complexo soja (US\$30,96 bilhões); carnes (US\$16,80 bilhões); complexo sucroalcooleiro (US\$13,72 bilhões); produtos florestais (US\$9,63 bilhões); e cereais, farinhas e preparações (US\$7,25 bilhões). Segundo ao autor, os cinco agregados responderam por $78,4 \%$ das vendas externas do agronegócio nacional.

Mesmo possuindo elevado grau de industrialização, o estado de São Paulo tem no agronegócio um setor muito expressivo. Estima-se o PIB estadual do setor em R $\$ 213$ bilhões para 2013, cerca de 20\% do PIB do agronegócio brasileiro, entretanto, o agronegócio paulista representa aproximadamente $15 \%$ do PIB total do estado (CEPEA, 2014). O setor gera em torno de 15\% dos empregos formais da economia paulista, sendo que a maior parte está concentrada na agroindústria (35\%) e serviços (47\%). Já o segmento de produção agropecuária responderia por 16\% dos empregos formais, todavia esses números não incluem o trabalho da mão de obra familiar, fundamental nas micro e pequenas propriedades.

Ainda segundo o CEPEA (2014b), as vantagens comparativas de São Paulo fazem com que o estado tenha um agronegócio em que predominam os segmentos agroindustrial e de serviços, com $41,5 \%$ e $43 \%$ do PIB do setor no ano de 2013, enquanto que a agropecuária (“dentro da porteira”) representou 9,5\% do PIB do agronegócio estadual. Comparativamente ao PIB do agronegócio nacional o segmento agropecuário paulista representa somente 5,4\% do PIB desse segmento no Brasil como um todo. Já o PIB da agroindústria paulista representa quase $30 \%$ do PIB agroindustrial do País, enquanto que o segmento de insumos agropecuários representa $18 \%$ do equivalente nacional.

Embora represente menos de 10\% do PIB do agronegócio paulista e 1,4\% do PIB total, o segmento agropecuário tem grande importância no aspecto econômico dos municípios, pois foi o principal componente de 28,7\% das 645 cidades do estado em 2003 de acordo com a Fundação SEADE (2006). Já o setor Agroterciário (ou agroserviços) é o principal componente de $25 \%$ dos municípios (Figura 1). Outro aspecto relevante é que cerca de 87\% do Valor Adicionado da Agropecuária estadual são gerados por municípios com populações até 100 mil habitantes (BESSA; APARICIO, 2013). 


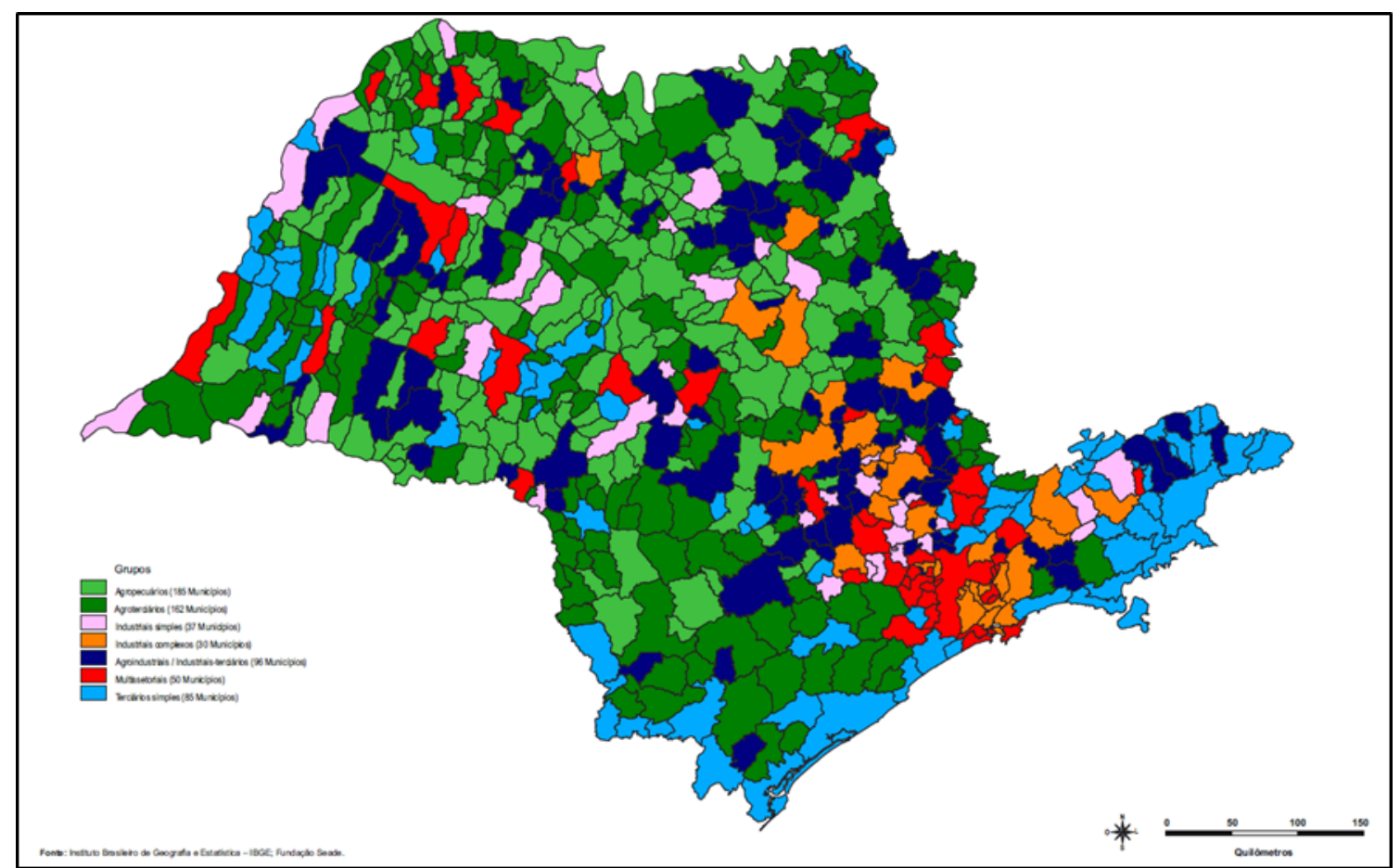

Figura 1. Participação dos Setores no Produto Interno Bruto Municipal

Fonte: SEADE, 2006

Quando se permite observar a distribuição do setor agrícola pelo território do Estado de São Paulo, envolvendo em torno de 324 mil (SÃO PAULO, 2009) estabelecimentos de produção, são encontradas diferentes combinações entre especialização e concentração geográfica em diversas atividades (ou produtos).

Um dos principais autores a explorar este tema foi Gonçalves (2004; 2005; 2006a; 2006b; 2009). Parte dos seus trabalhos apontavam a importância da esfera regional e local ao afirmar que embora a estrutura da agricultura e pecuária paulista tenha sido correntemente apresentada como marcada pela diversificação, tendo em vista a relevante participação estadual no contexto nacional numa grande variedade de produtos, havia no estado um setor agrícola moderno, sustentado em uma agropecuária diferenciada regionalmente pela especialização produtiva.

A partir de estudos sobre a Produção Agropecuária de lavouras e criações em função de sua relevância quantitativa e econômica para a diferentes regiões e para o estado, segundo Gonçalves (2006a; 2006b) o setor estaria alicerçado em três eixos ordenadores:

a) Cadeias de produção especializadas de dimensão estadual, tais como a cana de açúcar e carne bovina, que representaram respectivamente 46,7\% e 11\% do Valor da Produção Agropecuária do estado em 2013 (TSUNESHIRO et al., 2014) e ocupam em torno de 80\% da área agrícola do estado;

b) Grandes cadeias de produção concentradas num conjunto de regiões, formando espaços ocupados por atividades consistentemente especializadas mas que assumem perfis regionais mais específicos (citros, florestas econômicas; grãos e fibras, café e leite);

c) Pequenas cadeias de produção especializadas localmente (amendoim, banana, abacaxi) desenvolvidas a partir de singularidades baseadas no aproveitamento de oportunidades sócio-edafoclimáticas das diferentes microrregiões paulistas. Embora tenham reduzido impacto na renda bruta agropecuária total, tais cadeias apresentam elevada importância local, seja porque desenvolveram complementaridade com uma grande cadeia de produção, ou porque construíram estruturas produtivas locais modernas.

A metodologia utilizada por Gonçalves (2006a; 2006b) na obtenção dessa tipologia de cadeias produtivas assemelha-se, em parte, àquela utilizada por Suzigan et al. (2004) para identificar e delimitar geograficamente Sistemas Locais de Produção (SLP), embora a natureza das variáveis seja diferente, assim como a complexidade do modelo matemático. Estes autores, baseando-se nos trabalhos de 
Krugman (1991) e de Audretsch e Feldman (1996), utilizaram dados da RAIS/MTE ${ }^{2}$ e PIA/IBGE ${ }^{3}$ com o intuito de elaborar indicadores de concentração geográfica em função de classes de indústrias (Gini locacional) e de localização de atividades industriais (Quociente Locacional).

Os trabalhos de Marion Filho et al. (2011; 2015) analisaram a concentração regional e especialização na produção de leite do Rio Grande do Sul, identificando microrregiões nos períodos de 1990 a 2007 e 1990 a 2010. Para tanto, a especialização foi determinada a partir do Quociente Locacional (QL) e a concentração avaliada baseando-se em resultados de Gini Locacional. Os autores utilizaram a metodologia delineada por Suzigan et al. (2003; 2004), e variáveis relacionadas ao Valor Adicionado da Agricultura e Valor da Produção de Leite nas microrregiões geográficas determinadas pelo IBGE.

Garcia et al. (2011) entendem que a proximidade geográfica representa um estímulo relevante na geração e difusão de novos conhecimentos e capacitações entre os agentes econômicos, principalmente quando se verifica a presença concentrada de instituições de CT\&I, tendo em vista a possibilidade da oferta de um conjunto de insumos inovativos que se somam aos esforços de desenvolvimento tecnológico interno das empresas. Segundo Audretsch (1998), instituições de ensino e pesquisa (universidades, escolas tecnológicas e centros de $\mathrm{P} \& \mathrm{D}$ ) são responsáveis por parte dos transbordamentos de conhecimento, que tendem a ser restritos ao espaço geográfico e, com isso, podem ser considerados uma fonte de vantagem comparativa.

A concentração regional expressa a distribuição espacial de atividades em determinado espaço territorial, sendo que Alfred Marshall foi o primeiro a desenvolver a ideia dos benefícios da concentração por meio das externalidades (MARION FILHO et al., 2015). Para o autor, “as aglomerações favorecem o surgimento de uma força de trabalho especializada e a expansão do conhecimento, que ao difundir-se, ajuda na criação de novas tecnologias”.

Segundo Salles-Filho et al. (2011), o setor agrícola é caracterizado por uma maior integração entre a geração e adoção de conhecimento, pois a pesquisa agrícola historicamente esteve articulada com o setor produtivo, mesmo que isto tenha ocorrido por intermédio de instrumentos e instituições de assistência técnica e extensão rural. Seu conjunto, incluindo setores a montante (insumos) e a jusante (beneficiamento, industrialização e distribuição) poderia ser visto como um Sistema Setorial de Inovação ${ }^{4}$.

Para os autores, a unidade de produção agrícola (ou estabelecimento agropecuário), pode ser considerada como fonte de inovação na agricultura, embora não seja um local dinâmico de criação de novo conhecimento é o "locus no qual todo conjunto de tecnologias agrícolas se reúne e se consubstancia, com uma base técnica coerente de produção". Ponderam ainda que "o learning by using e o learaning by doing são as principais formas de influência dessa fonte na base técnica de produção na agricultura”.

Entretanto, as fontes institucionais públicas, normalmente são responsáveis pela geração e difusão de tecnologia genética e de práticas agrícolas (técnicas de cultivo e criação), além de parte importante da pesquisa básica voltada ao conhecimento novo para o setor agrícola. Salles-Filho et al. (2011) consideram que em função da forma e conteúdo aplicado desse conhecimento (e tecnologias), a pesquisa agrícola poderia ser exemplo de sucesso na articulação entre governo, pesquisa e produção.

Algo que chama a atenção no Estado de São Paulo é a robustez e distribuição geográfica de sua infraestrutura de Ciência, Tecnologia e Inovação (CT\&I) com atuação junto ao setor agrícola e agroindustrial. O estado possui a mais ampla estrutura de pesquisa do Sistema Nacional de Pesquisa Agropecuária (SNPA), sendo a Agência Paulista de Tecnologia dos Agronegócios (APTA) a principal Organização Estadual de Pesquisa Agropecuária pertencente a esse sistema (SICSÚ; SILVEIRA, 2013).

Por sua vez, essa infraestrutura, também denominada na literatura por Sistema Paulista de Ciência, Tecnologia e Inovação Agrícola (SALLES et al., 2011), embora inexista formalmente, é formada por um conjunto de instituições públicas (APTA, UNESP, UNICAMP, USP, FATEC, UFSCAR, Embrapa,

\footnotetext{
${ }^{2}$ RAIS - Relação Anual de Informações Sociais, cuja coleta e tabulação é realizada pelo Ministério do Trabalho e Emprego.

${ }^{3}$ PIA - Pesquisa Industrial Anual do Instituto Brasileiro de Geografia e Estatística (IBGE).

${ }^{4} \mathrm{O}$ conceito de sistema setorial de inovações permite a utilização de uma visão multidimensional integrada e dinâmica da inovação em seus setores. Sistemas setoriais apresentam três dimensões que afetam tanto a geração e adoção de novas tecnologias quanto a organização da inovação e produção nos seguintes níveis setoriais: conhecimento, atores e redes e instituições (MALERBA, 2003).
} 
IFCT) e particulares (FGV, UNOESTE, UNIFRAN, UNISA, UNIP, UNICASTELO, FUNDECITRUS, CTC-CANA), com atuação em ensino e/ou pesquisa, que estão distribuídas pelo território estadual atuando em diferentes áreas das Ciências Agrárias, Medicina Veterinária, Zootecnia e Recursos Pesqueiros, Administração e Gestão Rural, Economia Agrícola, Ciência e Engenharia de Alimentos.

Conforme abordado por Salles Filho, Bonacelli e Mello (2000), a partir da década de 1990, houve uma busca mundial de alternativas de modelos organizacionais para as instituições de pesquisa, alicerçada por um processo de transformação produtiva, comercial e financeira, no qual a globalização ou mundialização teve implicações evidentes sobre a forma de se fazer ciência, tecnologia e inovação com implicações. No Brasil, em âmbito federal e estadual não foi diferente. Exemplo deste fato foi a redefinição da trajetória dos Institutos da SAA-SP, que passou por processos de transformação organizacional desde 1998, culminando na criação da APTA.

Assim, no Estado de São Paulo foi realizada uma ampla mudança organizacional iniciando pela criação de uma agência pública de pesquisa em agronegócios, vinculando em sua estrutura as Organizações Públicas de Pesquisa (OPP) anteriormente ligadas à pasta da Secretaria de Agricultura e Abastecimento, concentrando as decisões hierárquicas e administrativas.

Posteriormente, foi colocado em prática um processo de distribuição de atividades passando de níveis hierárquicos superiores para níveis inferiores dentro da mesma pessoa jurídica, ocorrendo uma distribuição de competências, sempre com a presença do vínculo de subordinação e hierarquia, seguindo conceitos da ‘desconcentração administrativa’ (MEDAUAR, 2001; ARAÚJO NETO, 2005).

A redistribuição de atividades e competências foi efetivada com a reorganização da Agência Paulista de Tecnologia dos Agronegócios (APTA), a partir do Decreto 46.488/2002 do Governo de Estado (SÃO PAULO, 2002), que a definiu como "instituição pública de pesquisa da Secretaria de Agricultura e Abastecimento" com a missão de "gerar, adaptar e transferir conhecimentos científicos e tecnológicos para os agronegócios, visando o desenvolvimento socioeconômico e o equilíbrio do meio ambiente”.

A APTA foi composta por unidades de coordenação, planejamento e avaliação; "unidades de realização de pesquisa e desenvolvimento com abrangência estadual”; e "unidades de realização de pesquisa e desenvolvimento regional como centros de pesquisa e desenvolvimento focados nas cadeias de produção dos agronegócios locais: os Polos Regionais de Desenvolvimento Tecnológico dos Agronegócios” (SÃO PAULO, 2002).

Por definição, os Polos Regionais de Desenvolvimento Tecnológico são "unidades multidisciplinares de pesquisa e desenvolvimento, com sede e abrangência da atuação localizadas numa região paulista, objetivando gerar e transferir conhecimentos científicos e tecnológicos com foco nas demandas das cadeias de produção regionais, sempre com o suporte dos centros de excelência dos institutos de pesquisa da APTA”.

Para Rio (2009) os Polos Regionais fazem parte de um conjunto de inovações organizacionais muito importantes que ocorreram na pesquisa agrícola paulista, "pois alteraram a estrutura de organização da APTA e dos institutos de pesquisa e promoveram a regionalização da pesquisa".

De acordo com Firetti e Veiga Filho (2012), em 2011 os quinze Polos Regionais respondiam por 25\% do total de 780 pesquisadores da APTA; 31\% dos projetos de pesquisa em andamento; 30,6\% do total de artigos completos publicados em periódicos; 20,4\% dos projetos financiados pela FAPESP (agência de fomento do governo de São Paulo); e 23\% dos projetos de pesquisa financiados pelo CNPq (agência de fomento do governo federal). A infraestrutura dessas unidades de pesquisa compreendia em torno de 11.000 hectares de áreas destinadas à conservação ambiental e pesquisa agropecuária.

Deve-se levar em consideração que a presença de pesquisadores permanentemente lotados nos Polos Regionais, e focados na resolução de problemas das cadeias de produção locais, tende a contribuir para uma melhor articulação entre os atores das cadeias produtivas, possibilitando a criação de sinergias e aprendizado por meio do contato e discussão frequente (interação entre atores), o que potencialmente amplia a eficiência e especialmente eficácia dos processos de difusão, comunicação a adoção de novas técnicas de produção e/ou comercialização.

Todavia, Gonçalves (2006c) entende que, de modo geral, o tratamento dado à regionalidade nas ações do Governo do Estado de São Paulo revelava problemas de convergência e foco, tendo em vista a 
“enorme fragmentação de ações locais dos vários órgãos, não por serem vinculados a secretarias e instituições diferentes, mas por não haver qualquer nexo que compatibilizasse os diversos espaços geográficos, levando cada qual a planejar e a agir como se os demais órgãos não existissem”.

\section{OBJETIVOS}

Este trabalho teve por objetivo identificar a especialização produtiva da agropecuária paulista em diferentes regiões do estado, com a finalidade fundamental de realizar-se ensaio metodológico (bases de dados, regionalização e técnica de agrupamento) para subsidiar, a posteriori, a identificação e caracterização de sistemas locais de produção e inovação agrícola utilizando metodologias delineadas por Suzigan et al (2004). Concomitantemente, os resultados obtidos podem orientar atores públicos de CT\&I no desenvolvimento de ações institucionais de geração, adaptação e transferência de conhecimentos científicos e tecnológicos.

\section{METODOLOGIA}

O artigo explora as características da agricultura paulista no que ser refere à produção agropecuária desenvolvida em diferentes regiões do Estado de São Paulo, compreendendo questões relacionadas à produção de atividades agropecuárias; singularidades e especialização regional da agricultura.

Na delimitação territorial das regiões foram utilizadas as abrangências regionais dos Polos de Desenvolvimento Tecnológico dos Agronegócios (Figura 2), pertencentes à estrutura da Agência Paulista de Tecnologia dos Agronegócios, tendo em vista uma das finalidades do trabalho residir em subsídios às ações de pesquisa e transferência realizadas nessas unidades.

Como fontes de dados secundários utilizaram-se as "Estatísticas da Produção Agrícola”, do ano de 2015 (IEA-APTA, 2013), especificamente a variável referente ao Valor da Produção Agropecuária (VPA) de 50 atividades (Dimensão Econômica). A metodologia utilizada pelo Instituto de Economia Agrícola (IEA-APTA) para o cálculo do VPA considera o mesmo valor unitário dos produtos independentemente da região em que foi produzido, tornando-se uma constante. Dessa forma, a utilização do VPA da forma preconizada neste estudo resulta na participação regional em relação à produção estadual.

Foram calculadas frequências relativas e percentuais que expressaram a participação das regiões na produção estadual dos 50 produtos analisadas, refletindo a relevância do produto agropecuário para a região de abrangência do PRDTA e em relação ao Estado, obtendo-se um mosaico de distribuição no qual foi possível obter aglomerações produtivas e indicar com quais regiões e produtos ocorrem a concentração da produção. No cálculo das frequências relativas, utilizou-se a seguinte fórmula:

$$
\mathrm{PRPA}_{i j}=\frac{V P A_{i j}}{\sum V P A_{-} S P}
$$

Onde:

PRPA $_{\mathrm{ij}}=$ participação relativa do produto agropecuário “i” na região “j” do Estado de São Paulo

$\mathrm{VPA}_{\mathrm{ij}}=$ valor da produção agropecuária do produto “i” na região “j”;

VPA_SP ${ }_{i}=$ somatório do valor da produção agropecuária do produto “i” no Estado de São Paulo.

Para visualizar a distribuição da produção agrícola, no âmbito dos 15 PRDTA, os resultados de frequência relativa obtidos foram tabulados, sistematizados, e posteriormente submetidos à técnica estatística multivariada de agrupamento two-way-joining (HARTIGAN, 1975; HAIR et al., 2009), utilizando o software estatístico STATISTICA 8.0 (STATSOFT, 2007). Os resultados foram organizados em 08 classes de frequência com intervalos de 0,12 (12\%), sendo que cada classe recebeu uma cor correspondente, diferenciando-as, e facilitando sua observação. 
Para Firetti et al. (2012), essa técnica de agrupamento torna-se de grande utilidade pelo fato de possibilitar o agrupamento simultâneo de casos (regiões) e variáveis (produtos agropecuários), contribuindo para a descoberta de padrões significativos de agrupamentos (clusters). 


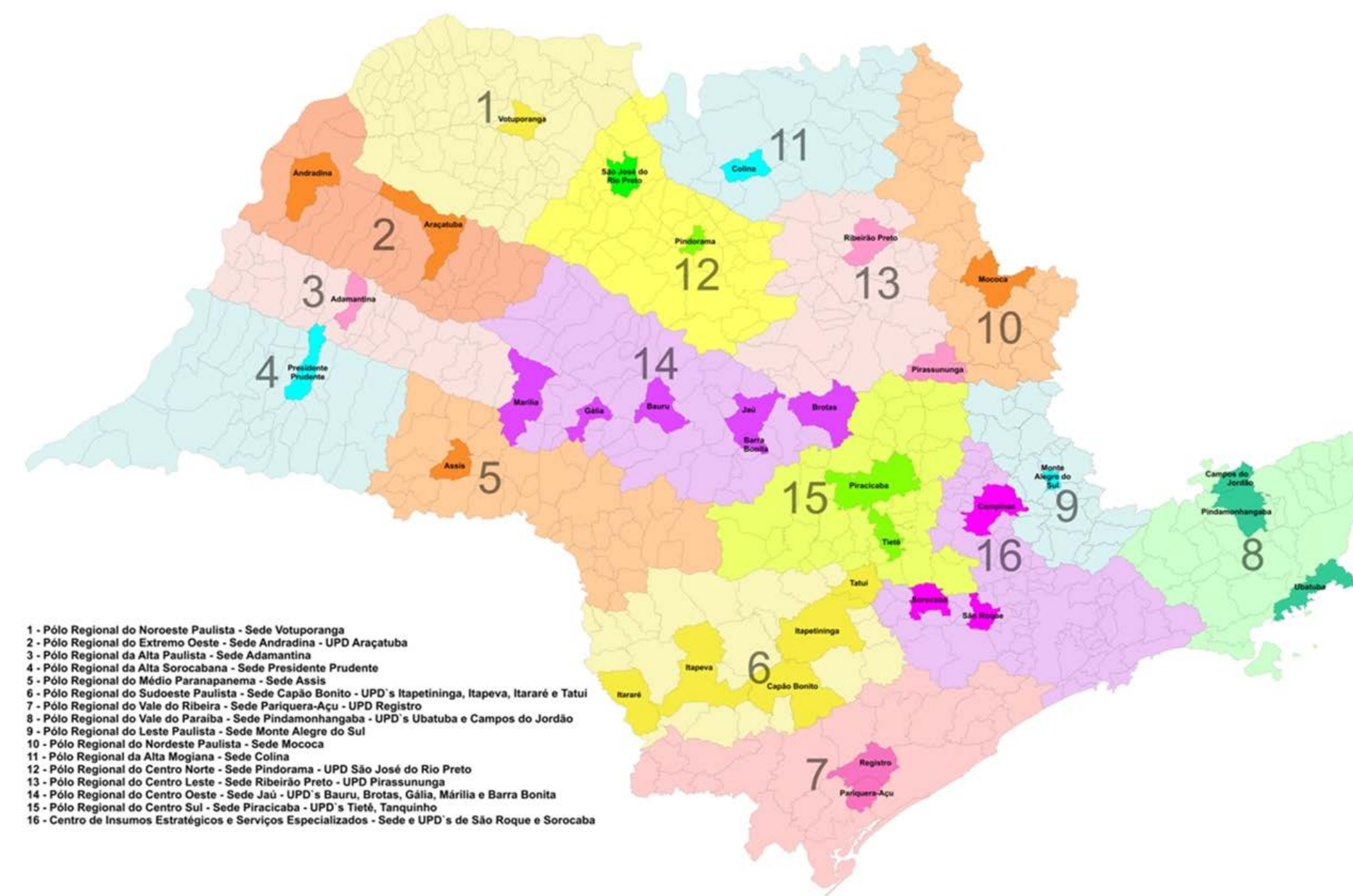

Figura 2. Abrangência geográfica dos Polos Regionais de Desenvolvimento Tecnológico dos Agronegócios Fonte: DGE-APTA (2011). 


\section{RESULTADOS OBTIDOS}

A análise inicial dos resultados utilizando a frequência relativa percentual das quantidades produzidas nas regiões em relação ao total da produção estadual, podem ser observadas na Tabela 1. Todavia, em função da grande quantidade de informações, tem-se dificuldade na análise dos resultados, diferenciação das realidades regionais, e visualização do mosaico de concentração da produção regional agropecuária. Justamente para facilitar esse tipo de análise com número elevado de casos (regiões) e variáveis (produtos agropecuários), é que se utilizou o agrupamento two-way-joinning.

Desta forma, com a técnica estatística multivariada two-way-joinning, foi possível observar a relação entre a produção regional e a produção estadual (Figura 3) aponta a existência no Estado de São Paulo de aglomerações produtivas e concentração da produção estadual em algumas regiões específicas.

Em 18 atividades agropecuárias pelo menos de 60 a 70\% da produção estadual está concentrada numa das 15 regiões analisadas (abobrinha; alface; beterraba; cenoura; repolho; figo de mesa; caqui; morango; arroz em casca; banana; algodão em caroço; trigo; triticale; pêssego de mesa; goiaba para indústria; limão; manga; e abacaxi), apontando elevada concentração da produção em determinadas regiões, e consequentemente, grande interesse público do ponto de vista de abastecimento, especialmente no que diz respeito à abrangência da Sede da APTA Regional, em Campinas (olerícolas); Sudoeste Paulista (culturas de inverno) e Centro Norte (frutas tropicais).

Destaca-se o Sudoeste Paulista como a região de maior diversificação especializada do Estado, sendo, portanto, uma das principais produtoras agrícolas, pois apresenta 14 atividades em que tenha pelo menos 36\% do total da produção estadual, incluindo os principais grãos (milho, soja e feijão); olerícolas (abóbora, tomate e batata); além das culturas de inverno mencionadas anteriormente.

Observa-se na maioria das regiões a elevada concentração de uma atividade agrícola (acima de 72\%), tais como o Vale do Paraíba (arroz em casca); Vale do Ribeira (banana); Alta Paulista (ovos e casulos de seda); e Extremo Oeste (abacaxi). As demais regiões convivem com boas participações na produção estadual, entre 36\% e 48\%, tais como Noroeste Paulista (batata e café); Médio Paranapanema (soja e mandioca para indústria); Centro Sul (mel e carne suína); Noroeste Paulista (borracha e tomate indústria); Alta Mogiana (sorgo) e Leste Paulista (morango).

As regiões Centro Oeste e Alta Sorocabana possuem participação entre $24 \%$ e $36 \%$ em algumas atividades agrícolas; enquanto a região Centro Leste apresenta as menores participações entre as 15 regiões analisadas no Estado de São Paulo.

Estes resultados vão de encontro ao apontado por Gonçalves (2006a; 2006b), ao afirmar que a agricultura paulista possuía diversificação regional, ao mesmo tempo que apresentava atividades especializadas. Seus trabalhos se baseavam em estudos sobre o Valor da Produção Agropecuária de lavouras e criações em função de sua relevância econômica para a diferentes regiões e para o estado, em que o setor estaria alicerçado em três Eixos Ordenadores: (A) Cadeias de produção especializadas de dimensão estadual; (B) Grandes cadeias de produção concentradas num conjunto de regiões; (C) Pequenas cadeias de produção especializadas localmente.

Entretanto, na regionalização adotada, que leva em conta a territorialidade dos Polos Tecnológicos da APTA, inexiste o Eixo (A) formados por Cadeias de Produção de Dimensão Estadual, ou seja, presentes em praticamente todas as regiões e que abarcam grandes áreas territoriais. Na verdade, observase que dentre as 50 atividades analisadas, 09 delas (abacate, carne suína, mandioca de mesa, cana, laranja para indústria, laranja de mesa, carne bovina, leite e melancia) possuem distribuição semelhantes àquela atribuída ao eixo (B), embora não sejam necessariamente "grandes cadeias de produção".

No caso específico do Eixo Ordenador (A), formado por Cadeias de Dimensão Estadual, Gonçalves et al. (2006a; 2006b) trabalharam com o Valor da Produção Agropecuária de diferentes regiões, e quase que invariavelmente, as produções de Carne Bovina e Cana-de-açúcar ocupavam sempre a primeira e segunda posição do ranqueamento ordenados de forma decrescente de valores em reais.

Importante evidenciar que esta distribuição espacial da produção é antagônica à encontrada no Estado do Paraná por Fuentes Llanillo et al. (2006) utilizando técnicas multivariadas de análise fatorial, no qual a principal constatação dos autores é que os grupos ou tipos de município com agricultura 
semelhante não ocorrem de forma aleatória ou dispersa, mas de forma organizada e caracterizando grandes

espaços

geográficos

contínuos. 
Tabela 1. Distribuição percentual da produção agropecuária nas regiões de abrangência dos Polos Regionais de Desenvolvimento Tecnológico dos Agronegócios (DDD-APTA). (continua...)

\begin{tabular}{|c|c|c|c|c|c|c|c|c|c|c|c|c|c|c|c|c|c|}
\hline & Sedes & $\begin{array}{l}\text { Extemo } \\
\text { Oeste }\end{array}$ & $\begin{array}{l}\text { Noroeste } \\
\text { Paulista }\end{array}$ & $\begin{array}{c}\text { Alta } \\
\text { Paulista }\end{array}$ & $\begin{array}{c}\text { Alta } \\
\text { Sorocabana }\end{array}$ & $\begin{array}{c}\text { Sudoeste } \\
\text { Paulista }\end{array}$ & $\begin{array}{l}\text { Centro } \\
\text { Norte }\end{array}$ & $\begin{array}{c}\text { Médio } \\
\text { Paranapanema }\end{array}$ & $\begin{array}{c}\text { Alta } \\
\text { Mogiana }\end{array}$ & $\begin{array}{l}\text { Centro } \\
\text { Leste }\end{array}$ & $\begin{array}{c}\text { Nordeste } \\
\text { Paulista }\end{array}$ & $\begin{array}{l}\text { Centro } \\
\text { Oeste }\end{array}$ & $\begin{array}{c}\text { Centro } \\
\text { Sul }\end{array}$ & $\begin{array}{l}\text { Leste } \\
\text { Paulista }\end{array}$ & $\begin{array}{l}\text { Vale do } \\
\text { Paraiba }\end{array}$ & $\begin{array}{l}\text { Vale do } \\
\text { Ribeira }\end{array}$ & ESTADO \\
\hline Abacate & $4,44 \%$ & $0,62 \%$ & $1,08 \%$ & $3,95 \%$ & $0,43 \%$ & $2,31 \%$ & $3,31 \%$ & $17,06 \%$ & $0,99 \%$ & $10,60 \%$ & $27,66 \%$ & 6,05\% & $10,51 \%$ & $10,75 \%$ & $0,24 \%$ & & $100,00 \%$ \\
\hline Abacaxi & $0,70 \%$ & $69,84 \%$ & $3,58 \%$ & $1,79 \%$ & $3,88 \%$ & $2,58 \%$ & $2,71 \%$ & & $1,65 \%$ & $0,38 \%$ & $1,26 \%$ & $11,43 \%$ & 0,09\% & & & $0,10 \%$ & $100,00 \%$ \\
\hline Abobora & $9,60 \%$ & $3,31 \%$ & $2,02 \%$ & $17,10 \%$ & $8,11 \%$ & $41,09 \%$ & $1,14 \%$ & $1,16 \%$ & & $0,55 \%$ & $3,64 \%$ & $2,56 \%$ & $1,81 \%$ & $1,46 \%$ & $1,29 \%$ & $5,16 \%$ & $100,00 \%$ \\
\hline Abobrinha & $61,35 \%$ & $2,96 \%$ & $2,23 \%$ & $3,10 \%$ & $1,09 \%$ & $9,70 \%$ & $1,74 \%$ & $0,80 \%$ & $0,71 \%$ & $2,07 \%$ & $2,91 \%$ & $1,57 \%$ & 1,63\% & $5,81 \%$ & $0,97 \%$ & $1,37 \%$ & $100,00 \%$ \\
\hline Alface & $83,20 \%$ & $0,50 \%$ & $1,32 \%$ & $0,48 \%$ & $1,17 \%$ & $1,12 \%$ & $0,94 \%$ & $0,35 \%$ & $0,26 \%$ & $0,63 \%$ & $1,51 \%$ & $2,41 \%$ & 2,29\% & $1,84 \%$ & $1,36 \%$ & $0,62 \%$ & $100,00 \%$ \\
\hline Algodao em caroco & & & $0,59 \%$ & $1,98 \%$ & $21,59 \%$ & $63,84 \%$ & & & & $2,43 \%$ & & & 9,57\% & & & & $100,00 \%$ \\
\hline Amendoim em casca & & $3,26 \%$ & $5,53 \%$ & $18,22 \%$ & $14,72 \%$ & $0,00 \%$ & $19,35 \%$ & $11,24 \%$ & $7,51 \%$ & $10,79 \%$ & $0,19 \%$ & $9,18 \%$ & & $0,00 \%$ & & $0,00 \%$ & $100,00 \%$ \\
\hline Arroz em casca & $0,01 \%$ & & $0,06 \%$ & $0,00 \%$ & $0,06 \%$ & $7,18 \%$ & $0,32 \%$ & $6,54 \%$ & $0,85 \%$ & $1,22 \%$ & $0,34 \%$ & 0,05\% & 0,54\% & $0,82 \%$ & $70,87 \%$ & $11,13 \%$ & $100,00 \%$ \\
\hline Banana & $1,50 \%$ & $1,42 \%$ & $6,03 \%$ & $0,65 \%$ & $0,46 \%$ & $2,61 \%$ & $1,62 \%$ & $2,53 \%$ & $0,15 \%$ & $0,20 \%$ & $0,56 \%$ & $1,04 \%$ & 0,76\% & $0,94 \%$ & $3,05 \%$ & $76,48 \%$ & $100,00 \%$ \\
\hline Batata & $3,34 \%$ & & & $0,01 \%$ & & $50,23 \%$ & & $3,03 \%$ & $0,25 \%$ & $1,38 \%$ & $37,12 \%$ & & $\begin{array}{l}0,10 \% \\
\end{array}$ & $4,48 \%$ & $0,05 \%$ & & $100,00 \%$ \\
\hline Batata doce & $22,16 \%$ & $27,98 \%$ & $0,39 \%$ & $8,88 \%$ & $25,34 \%$ & $1,01 \%$ & $4,53 \%$ & $1,42 \%$ & $4,74 \%$ & $0,30 \%$ & & $1,66 \%$ & $0,64 \%$ & $0,34 \%$ & $0,31 \%$ & $0,30 \%$ & $100,00 \%$ \\
\hline Beterraba & $80,19 \%$ & $0,05 \%$ & $0,14 \%$ & $0,04 \%$ & $0,23 \%$ & $3,36 \%$ & $0,04 \%$ & $0,04 \%$ & & $0,07 \%$ & $14,85 \%$ & 0,03\% & 0,52\% & $0,12 \%$ & $0,26 \%$ & $0,08 \%$ & $100,00 \%$ \\
\hline Borracha & $0,00 \%$ & $4,95 \%$ & $43,75 \%$ & $4,66 \%$ & $2,46 \%$ & & $23,06 \%$ & $0,21 \%$ & $14,48 \%$ & $0,13 \%$ & $0,76 \%$ & 5,03\% & $0,42 \%$ & $0,00 \%$ & $0,00 \%$ & $0,09 \%$ & $100,00 \%$ \\
\hline Cafe beneficiado & $0,31 \%$ & $0,48 \%$ & $0,22 \%$ & $3,03 \%$ & $0,44 \%$ & $0,87 \%$ & $0,39 \%$ & $12,62 \%$ & $1,81 \%$ & $1,32 \%$ & $42,33 \%$ & $19,89 \%$ & $1,88 \%$ & $14,38 \%$ & $0,02 \%$ & $0,01 \%$ & $100,00 \%$ \\
\hline Cana-de-acucar & $0,92 \%$ & $8,71 \%$ & $9,41 \%$ & $4,28 \%$ & $6,77 \%$ & $1,31 \%$ & $11,72 \%$ & $7,00 \%$ & $14,92 \%$ & $12,07 \%$ & $5,67 \%$ & $10,08 \%$ & 6,48\% & $0,61 \%$ & $0,05 \%$ & $0,00 \%$ & $100,00 \%$ \\
\hline Caqui & $62,82 \%$ & $0,13 \%$ & $0,08 \%$ & $0,06 \%$ & $0,34 \%$ & $25,41 \%$ & & $0,07 \%$ & & $0,02 \%$ & & $0,16 \%$ & : & $7,89 \%$ & $1,47 \%$ & $1,20 \%$ & $100,00 \%$ \\
\hline Carne bovina & $1,83 \%$ & $8,15 \%$ & $14,19 \%$ & $7,81 \%$ & $15,75 \%$ & $6,76 \%$ & $5,08 \%$ & $6,59 \%$ & $1,96 \%$ & $2,19 \%$ & $4,70 \%$ & 9,81\% & $5,47 \%$ & $3,55 \%$ & $4,82 \%$ & $1,35 \%$ & $100,00 \%$ \\
\hline Carne de frango & $9,88 \%$ & $0,02 \%$ & $4,80 \%$ & $0,18 \%$ & $0,66 \%$ & $9,85 \%$ & $5,98 \%$ & $0,42 \%$ & $4,16 \%$ & $7,71 \%$ & $10,16 \%$ & 6,64\% & $22,58 \%$ & $16,96 \%$ & $0,00 \%$ & & $100,00 \%$ \\
\hline Carne suina & $15,43 \%$ & $0,66 \%$ & $0,94 \%$ & $1,68 \%$ & $0,64 \%$ & $6,47 \%$ & $2,33 \%$ & $14,10 \%$ & $3,87 \%$ & $4,42 \%$ & $8,69 \%$ & 5,81\% & $26,54 \%$ & $8,36 \%$ & $0,02 \%$ & $0,02 \%$ & $100,00 \%$ \\
\hline Casulo & & & $0,86 \%$ & $53,32 \%$ & $25,39 \%$ & $0,69 \%$ & & & & & & $14,42 \%$ & 5,32\% & & & & $100,00 \%$ \\
\hline Cebola & $27,05 \%$ & $0,81 \%$ & & $0,38 \%$ & $0,03 \%$ & $24,62 \%$ & $26,06 \%$ & & & & $20,67 \%$ & & $\begin{array}{l}0,04 \% \\
\end{array}$ & & $0,05 \%$ & $0,29 \%$ & $100,00 \%$ \\
\hline Cenoura & 79,52\% & $0,09 \%$ & $0,12 \%$ & $0,04 \%$ & $0,23 \%$ & $3,94 \%$ & $0,07 \%$ & $0,11 \%$ & & & $13,94 \%$ & $0,12 \%$ & $\begin{array}{l}1,18 \% \\
\end{array}$ & $0,38 \%$ & $0,19 \%$ & $0,07 \%$ & $100,00 \%$ \\
\hline Feijao & $3,00 \%$ & $1,95 \%$ & $2,94 \%$ & $0,89 \%$ & $1,66 \%$ & $46,47 \%$ & $0,47 \%$ & $14,39 \%$ & $6,54 \%$ & $0,59 \%$ & $15,26 \%$ & $0,33 \%$ & $\begin{array}{l}2,73 \% \\
\end{array}$ & $1,79 \%$ & 0,62\% & 0,37\% & $100,00 \%$ \\
\hline Figo p/ mesa & $97,82 \%$ & & & & & & & & & & & & & $2,17 \%$ & $0,01 \%$ & & $100,00 \%$ \\
\hline Goiaba de mesa & $41,35 \%$ & $7,30 \%$ & $1,88 \%$ & $0,91 \%$ & $0,68 \%$ & $0,24 \%$ & $39,17 \%$ & $0,12 \%$ & $3,27 \%$ & $0,33 \%$ & & $0,90 \%$ & 1,17\% & $0,78 \%$ & $1,50 \%$ & $0,40 \%$ & $100,00 \%$ \\
\hline
\end{tabular}

Fonte: Adaptado de IEA-APTA (2016). 
Tabela 1. Distribuição percentual da produção agropecuária nas regiões de abrangência dos Polos Regionais de Desenvolvimento Tecnológico dos Agronegócios (DDD-APTA). (continuação...)

\begin{tabular}{|c|c|c|c|c|c|c|c|c|c|c|c|c|c|c|c|c|c|}
\hline & Sedes & $\begin{array}{l}\text { Extemo } \\
\text { Oeste }\end{array}$ & $\begin{array}{l}\text { Noroeste } \\
\text { Paulista }\end{array}$ & $\begin{array}{c}\text { Alta } \\
\text { Paulista }\end{array}$ & $\begin{array}{c}\text { Alta } \\
\text { Sorocabana }\end{array}$ & $\begin{array}{l}\text { Sudoeste } \\
\text { Paulista }\end{array}$ & $\begin{array}{l}\text { Centro } \\
\text { Norte }\end{array}$ & $\begin{array}{c}\text { Médio } \\
\text { Paranapanema }\end{array}$ & $\begin{array}{c}\text { Alta } \\
\text { Mogiana }\end{array}$ & $\begin{array}{l}\text { Centro } \\
\text { Leste }\end{array}$ & $\begin{array}{c}\text { Nordeste } \\
\text { Paulista }\end{array}$ & $\begin{array}{l}\text { Centro } \\
\text { Oeste }\end{array}$ & $\begin{array}{c}\text { Centro } \\
\text { Sul }\end{array}$ & $\begin{array}{l}\text { Leste } \\
\text { Paulista }\end{array}$ & $\begin{array}{l}\text { Vale do } \\
\text { Paraiba }\end{array}$ & $\begin{array}{l}\text { Vale do } \\
\text { Ribeira }\end{array}$ & ESTADO \\
\hline Goiaba p/ indústria & $0,16 \%$ & $0,41 \%$ & & $0,01 \%$ & & $0,16 \%$ & $74,59 \%$ & $0,73 \%$ & $6,96 \%$ & $5,24 \%$ & & $11,06 \%$ & & $0,69 \%$ & $0,00 \%$ & & $100,00 \%$ \\
\hline Laranja de mesa & $1,89 \%$ & $0,27 \%$ & $8,40 \%$ & $0,01 \%$ & $0,01 \%$ & $10,07 \%$ & $10,84 \%$ & $12,55 \%$ & $10,49 \%$ & $6,05 \%$ & $11,97 \%$ & $13,50 \%$ & $8,34 \%$ & $5,56 \%$ & $0,04 \%$ & $0,01 \%$ & $100,00 \%$ \\
\hline Laranja p/ industria & $1,89 \%$ & $0,27 \%$ & $8,40 \%$ & $0,01 \%$ & $0,01 \%$ & $10,07 \%$ & $10,84 \%$ & $12,55 \%$ & $10,49 \%$ & $6,05 \%$ & $11,97 \%$ & $13,50 \%$ & $8,34 \%$ & $5,56 \%$ & $0,04 \%$ & $0,01 \%$ & $100,00 \%$ \\
\hline Leite Refrigerado & $1,22 \%$ & $6,67 \%$ & $13,03 \%$ & $4,48 \%$ & $10,17 \%$ & $4,67 \%$ & $3,40 \%$ & $4,82 \%$ & $4,53 \%$ & $3,18 \%$ & $8,94 \%$ & $8,65 \%$ & $5,12 \%$ & $8,99 \%$ & $11,57 \%$ & $0,56 \%$ & $100,00 \%$ \\
\hline Limao & $3,09 \%$ & $0,72 \%$ & $10,02 \%$ & $0,04 \%$ & $0,25 \%$ & $1,50 \%$ & $70,32 \%$ & $0,19 \%$ & $0,61 \%$ & $0,48 \%$ & $2,03 \%$ & 0,90\% & $3,84 \%$ & $5,81 \%$ & $0,14 \%$ & $0,05 \%$ & $100,00 \%$ \\
\hline Mandioca p/ industria & $1,46 \%$ & $1,38 \%$ & $0,14 \%$ & $10,26 \%$ & $12,86 \%$ & $1,10 \%$ & $1,27 \%$ & $38,23 \%$ & $0,05 \%$ & $1,09 \%$ & $2,26 \%$ & 8,92\% 1 & $8,14 \%$ & $11,16 \%$ & $0,37 \%$ & $1,31 \%$ & $100,00 \%$ \\
\hline Mandioca p/ mesa & $19,48 \%$ & $4,79 \%$ & $2,64 \%$ & $2,80 \%$ & $6,37 \%$ & $9,47 \%$ & $11,63 \%$ & $3,52 \%$ & $1,43 \%$ & $2,28 \%$ & $2,14 \%$ & $2,21 \%$ & $7,44 \%$ & $16,15 \%$ & $3,71 \%$ & $3,92 \%$ & $100,00 \%$ \\
\hline Manga & $0,23 \%$ & $4,61 \%$ & $6,22 \%$ & $1,70 \%$ & $0,85 \%$ & $0,04 \%$ & $70,68 \%$ & $2,87 \%$ & $1,16 \%$ & $1,46 \%$ & 3,05\% & 1,87\% & $\begin{array}{l}0,22 \% \\
\end{array}$ & $5,03 \%$ & $0,00 \%$ & & $100,00 \%$ \\
\hline Maracujá & $7,77 \%$ & $1,57 \%$ & $0,96 \%$ & $19,73 \%$ & $4,83 \%$ & $14,42 \%$ & $4,23 \%$ & $1,22 \%$ & $0,05 \%$ & $0,08 \%$ & $1,99 \%$ & $12,30 \%$ & $1,51 \%$ & $7,40 \%$ & $3,08 \%$ & $18,86 \%$ & $100,00 \%$ \\
\hline Mel & $4,02 \%$ & $0,22 \%$ & $1,36 \%$ & $1,19 \%$ & $0,61 \%$ & $7,50 \%$ & $5,52 \%$ & $3,19 \%$ & $2,38 \%$ & $14,39 \%$ & $4,25 \%$ & 6,43\% & 35,18\% & $4,86 \%$ & $3,86 \%$ & $5,06 \%$ & $100,00 \%$ \\
\hline Melancia & $1,87 \%$ & $1,23 \%$ & $1,82 \%$ & $12,94 \%$ & $14,95 \%$ & $14,11 \%$ & $12,68 \%$ & $16,20 \%$ & & & & $17,14 \%$ & 7,00\% & $0,00 \%$ & & $0,05 \%$ & $100,00 \%$ \\
\hline Milho & $1,91 \%$ & $3,83 \%$ & $4,33 \%$ & $0,77 \%$ & $5,79 \%$ & $26,55 \%$ & 3,90\% & $23,28 \%$ & $5,55 \%$ & $2,32 \%$ & $9,67 \%$ & 3,37\% & $\begin{array}{l}3,72 \% \\
\end{array}$ & $4,05 \%$ & 0,52\% & $0,42 \%$ & $100,00 \%$ \\
\hline Morango & $59,77 \%$ & $0,04 \%$ & $0,29 \%$ & & & $3,12 \%$ & & & & & & 0,01\% & $\begin{array}{l}3,33 \% \\
\end{array}$ & $31,60 \%$ & $1,85 \%$ & & $100,00 \%$ \\
\hline Ovo & $6,06 \%$ & $7,11 \%$ & $0,42 \%$ & $51,56 \%$ & $6,68 \%$ & $5,36 \%$ & $1,51 \%$ & $6,49 \%$ & $0,41 \%$ & $3,16 \%$ & $0,83 \%$ & 3,67\% & $\begin{array}{l}3,18 \% \\
\end{array}$ & 2,93\% & $0,62 \%$ & $0,02 \%$ & $100,00 \%$ \\
\hline Pêssego de mesa & $17,89 \%$ & & & & & $60,28 \%$ & $0,11 \%$ & $1,13 \%$ & & $0,07 \%$ & $0,36 \%$ & & $0,41 \%$ & $15,36 \%$ & $0,86 \%$ & $3,53 \%$ & $100,00 \%$ \\
\hline Pimentao & 19,98\% & $1,41 \%$ & $1,73 \%$ & $1,45 \%$ & $0,97 \%$ & $31,10 \%$ & $3,15 \%$ & $9,57 \%$ & $0,19 \%$ & $1,04 \%$ & $1,32 \%$ & $22,36 \%$ & $1,60 \%$ & $2,80 \%$ & $0,90 \%$ & $0,45 \%$ & $100,00 \%$ \\
\hline Repolho & $86,67 \%$ & $0,24 \%$ & $0,08 \%$ & $0,08 \%$ & $0,28 \%$ & $2,54 \%$ & $0,07 \%$ & $0,03 \%$ & $0,04 \%$ & $0,07 \%$ & $7,72 \%$ & $0,18 \%$ & : $0,37 \%$ & $1,26 \%$ & 0,31\% & $0,05 \%$ & $100,00 \%$ \\
\hline Soja & $0,51 \%$ & $4,10 \%$ & $2,26 \%$ & $0,10 \%$ & $6,45 \%$ & $38,39 \%$ & \begin{tabular}{ll|}
$1,17 \%$ \\
\end{tabular} & $27,63 \%$ & $11,96 \%$ & $2,19 \%$ & $2,34 \%$ & 1,24\% & 1,22\% & $0,29 \%$ & $0,09 \%$ & $0,07 \%$ & $100,00 \%$ \\
\hline Sorgo & $2,91 \%$ & $10,93 \%$ & $8,23 \%$ & $0,11 \%$ & & $18,54 \%$ & $2,17 \%$ & $4,94 \%$ & $38,92 \%$ & $0,26 \%$ & $9,93 \%$ & $2,87 \%$ & : $0,05 \%$ & $0,15 \%$ & & & $100,00 \%$ \\
\hline Tangerina & $8,83 \%$ & $0,35 \%$ & $3,32 \%$ & $0,50 \%$ & $0,27 \%$ & $10,90 \%$ & $23,18 \%$ & $9,08 \%$ & $1,02 \%$ & $0,45 \%$ & $12,10 \%$ & $4,43 \%$ & 2,25\% & $16,40 \%$ & $1,73 \%$ & $5,20 \%$ & $100,00 \%$ \\
\hline Tomate de mesa & $9,64 \%$ & $0,20 \%$ & $2,41 \%$ & $0,60 \%$ & $0,17 \%$ & $54,20 \%$ & $0,17 \%$ & $2,31 \%$ & $0,03 \%$ & $1,20 \%$ & $1,93 \%$ & $3,07 \%$ & 0,93\% & $7,70 \%$ & $1,10 \%$ & $14,35 \%$ & $100,00 \%$ \\
\hline Tomate $\mathrm{p} /$ industria & \begin{tabular}{|l|l}
$0,01 \%$ \\
\end{tabular} & $18,80 \%$ & $27,72 \%$ & $8,38 \%$ & $4,16 \%$ & & $11,90 \%$ & $2,49 \%$ & $20,54 \%$ & $4,56 \%$ & & $1,41 \%$ & & & $0,03 \%$ & & $100,00 \%$ \\
\hline Trigo & $0,67 \%$ & & & & & $91,52 \%$ & & $5,62 \%$ & & & $0,37 \%$ & & $\begin{array}{l}1,09 \% \\
\end{array}$ & $0,16 \%$ & $0,56 \%$ & & $100,00 \%$ \\
\hline Triticale & $1,57 \%$ & & & & & $72,09 \%$ & & $21,18 \%$ & & & & & & $5,16 \%$ & & & $100,00 \%$ \\
\hline Uva de mesa & $29,45 \%$ & $0,06 \%$ & $18,67 \%$ & $2,20 \%$ & $0,22 \%$ & $38,81 \%$ & $0,19 \%$ & $0,00 \%$ & $0,04 \%$ & $0,09 \%$ & $0,22 \%$ & $0,07 \%$ & $2,57 \%$ & $7,39 \%$ & $0,01 \%$ & $0,02 \%$ & $100,00 \%$ \\
\hline
\end{tabular}

Fonte: Adaptado de IEA-APTA (2016). 


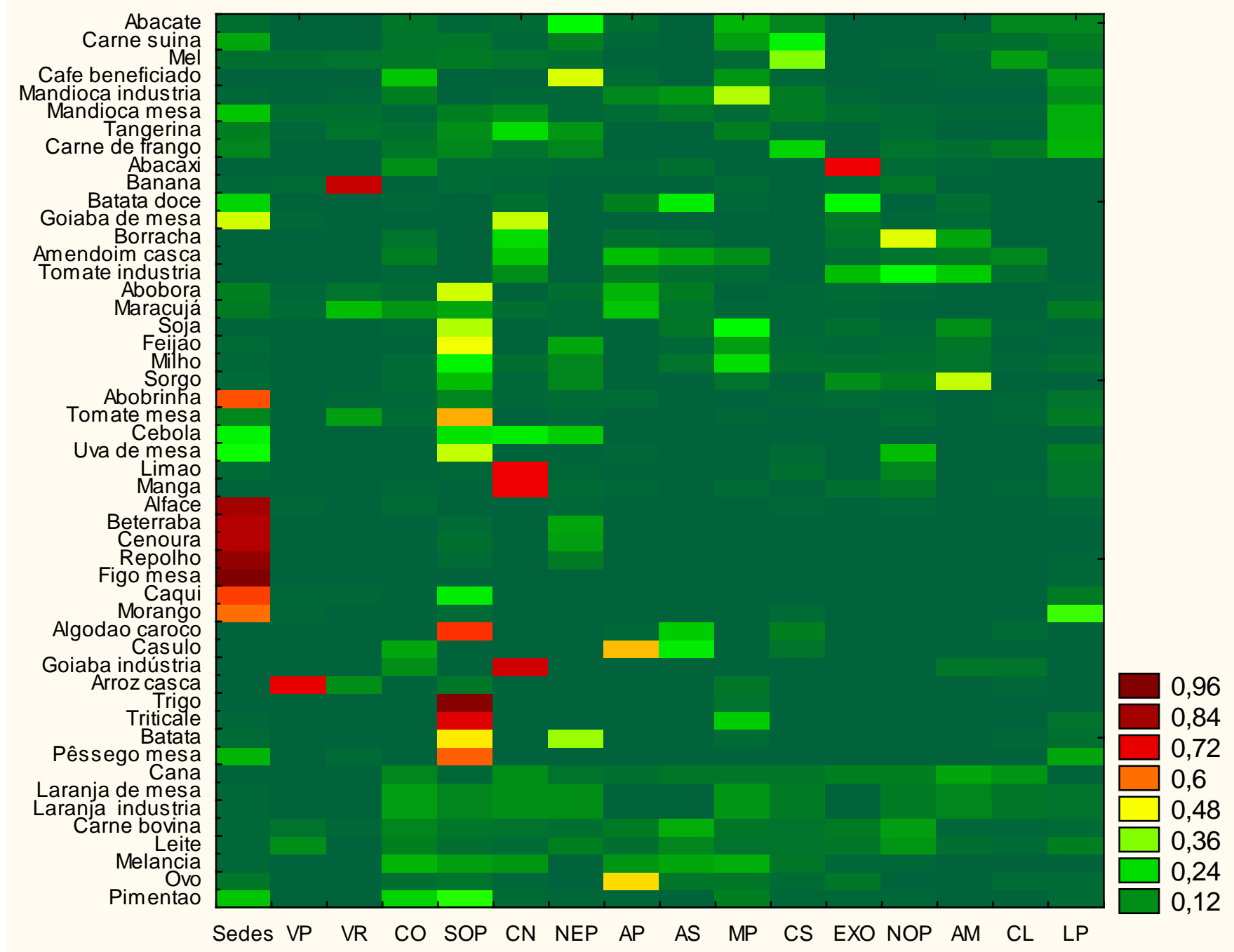

Figura 3. Distribuição de atividades agropecuárias nos PRDTA com base na produção regional em relação ao total do estado. (0,12=12\%) Fonte: Resultados da pesquisa 


\section{CONSIDERAÇÕES FINAIS}

O trabalho analisa as características da produção agropecuária em diferentes regiões do Estado de São Paulo, utilizando territorialização baseada na abrangência de atuação dos Polos Tecnológicos do Agronegócio, centros de pesquisa, desenvolvimento e inovação agrícola (PD\&I) da Secretaria de Agricultura e Abastecimento com a finalidade de atuação local.

Embora a regionalização adotada seja incompatível com outras formas de se pensar o território paulista de maneira oficial, tais como as Regiões Administrativas e de Governo do Estado de São Paulo, ou Mesorregiões e Microrregiões Geográficas delineadas pelo IBGE, fica evidenciado na Figura 3, o mosaico de atividades agropecuárias que mesclam a diversificação que ocorre dentro de algumas regiões, e ao mesmo tempo a concentração da produção de alguns produtos em regiões específicas.

Estes resultados nos levam a imaginar como tem sido a atuação dos Polos Tecnológico da APTA, e demais instituições de ensino e/ou pesquisa de nível superior, no tocante à sinergia com as cadeias de produção locais, ou mesmo dos Centros Avançados e Especializados dos Institutos de Pesquisa da APTA, formatados para atuar em cadeias produtivas específicas, mas que possuem sede de atuação por vezes distantes do local de produção.

Não obstante, deve ressaltar-se a recente desconcentração do ensino superior e tecnológico, juntamente com a pesquisa agrícola, realizado pelas Secretarias da Agricultura e Abastecimento, e Desenvolvimento, Ciência e Tecnologia, decorrente da criação e reorganização da Agência Paulista de Tecnologia dos Agronegócios; expansão do Centro Paula Souza (Escolas Técnicas e Faculdades Tecnológicas), e expansão da UNESP.

A ramificação e amplitude de cobertura dessas instituições constitui no aumento de possibilidades de ocorrência e criação de vantagens decorrentes da aglomeração da produção (economias externas) e de transbordamento do conhecimento (spillover tecnológico).

Ademais, seria natural entender que compatibilização de esforços na esfera regional auxiliaria o próprio desenvolvimento socioeconômico local, especialmente no setor primário da economia, o que em alguns casos significam a principal fonte de receita dos municípios. 


\section{REFERÊNCIAS BIBLIOGRÁFICAS}

ARAÚJO NETO, E. Curso de direito administrativo. São Paulo: Saraiva, 2005.

AUDRETSCH, Bruce. Agglomeration and the location of innovative activity. Oxford review of economic policy, v. 14, n. 2, p. 18-29, 1998.

AUDRETSCH, D.; FELDMAN, M. R\&D spillovers and the geography of innovation and production. The American Economic Review, n.86, p.630-640, 1996.

BESSA, V. C.; APARICIO, C. A. PIB dos municípios paulistas 2011. São Paulo: Fundação SEADE, 2013. 13 p.

CEPEA (CENTRO DE ESTUDOS AVANÇADOS EM ECONOMIA APLICADA). PIB Agro CEPEAUSP/CNA: Análise de 2013. Online. Disponível em: <http://cepea.esalq.usp.br/pib/>. Acesso em: 23 nov. 2014.

CEPEA (CENTRO DE ESTUDOS AVANÇADOS EM ECONOMIA APLICADA). PIB AGRO São

Paulo. Online. Disponível em: <http://cepea.esalq.usp.br/pibsp/>. Acesso em: 23 nov. 2014b.

DGE-APTA [Departamento de Gestão Estratégica - Agência Paulista de Tecnologia dos Agronegócios].

Polos Regionais de Desenvolvimento Tecnológicos dos Agronegócios - APTA Regional, Campinas:

DGE-APTA. 2011. Disponível em <http://www.dge.sp.gov.br>. Acesso em 14/10/2011.

FIRETTI, R. et al. Análise de variáveis estratégicas para o desenvolvimento da agropecuária da região do Pontal do Paranapanema. Revista de Economia e Sociologia Rural, Brasília, v. 50, n. 1, p. 141-156, 2012.

FIRETTI, R.; VEIGA-FILHO, A. A. Apta Regional: contribuição ao processo de descentralização do Sistema Paulista de Ciência, Tecnologia e Inovação Agrícola (SPInA). In: $\mathbf{5 0}^{\circ}$ Congresso da Sociedade Brasileira de Economia, Administração e Sociologia Rural, 2012, Vitória-ES. Congresso SOBER Agricultura e Desenvolvimento Rural com Sustentabilidade. Brásília-DF: SOBER, 2012. v. 50.

FUENTES LLANILLO, R. et al. Regionalização da agricultura do Estado do Paraná, Brasil. Ciência Rural, v. 36, n. 1, p. 120-127, 2006.

FUNDAÇÃO SISTEMA ESTADUAL DE ANÁLISE DE DADOS - SEADE. Atlas SEADE da economia paulista 2006. São Paulo: SEADE. Disponível em: <http://www.seade.gov.br/produtos/atlas/>. Acesso em: 20 nov. 2014.

GARCIA, R.C.; DA SILVA, C.F.; RIGHI, H.M. Dimensão regional dos esforços de ciência, tecnologia e inovação no Estado de São Paulo. In: BRENTANI, R. R.; BRITO CRUZ, C. H. (Orgs.). Indicadores de ciência, tecnologia e inovação em São Paulo 2010. São Paulo: FAPESP, 2011.

GONÇALVES, J. S. Agricultura paulista, especialização regional e políticas públicas. Análises e Indicadores do Agronegócio, São Paulo, v. 1, n. 10, out. 2006a. Disponível em: <http://www.iea.sp.gov.br/out/LerTexto.php?codTexto=7487>. Acesso em: dez. 2013.

GONÇALVES, J. S.; ANGELO, J. A.; SOUZA, S. A. M. Economias regionais paulistas no período 2005-2007: desconcentração na agropecuária com concentração na agricultura revelando diferenças estruturais. Informações Econômicas, v. 39, n. 2, p. 45-54, fev. 2009.

GONÇALVES, J.S. Inserção da dimensão da regionalidade na estrutura orçamentária do governo do Estado de São Paulo. Informações Econômicas, v.36, n.2, p.72-86, 2006b.

GONÇALVES, José Sidnei. Dinâmica da agropecuária paulista no contexto das transformações da sua agricultura. Informações Econômicas, v. 35, n. 12, p. 65-98, 2005.

GONÇALVES, J.S.; VICENTE, J.R. Desconcentração regional da renda agropecuária paulista no período 1999-2003. Informações Econômicas, v.34, n.10, p.57-71, 2004. 
HAIR, J.F., TATHAM, R.L., ANDERSON, R.E.; BLACK, W.C.; trad. Adonai Schlup Sant'Anna e Anselmo Chaves Neto. Análise multivariada de dados. Porto Alegre: Bookman, 6 a ed., 2009.

HARTIGAN, J.A. Clustering algorithms. John Wiley \& Sons, Inc., 1975.

IBGE, Fundação. Pesquisa Nacional por Amostragem de Domicílios 2006. Rio de Janeiro. IBGE. 2007b. Disponível em: <www.ibge.gov.br>. Acesso em 20 nov. 2014.

IEA - APTA (Instituto de Economia Agrícola - APTA). Estatísticas da Produção Agrícola 2011. São Paulo: IEA-APTA/SAA-SP, 2013. Disponível em: <http://www.iea.sp.gov.br/out/banco/menu.php>. Acesso em: 15/010/2014.

INSTITUTO BRASILEIRO DE GEOGRAFIA E ESTATÍSTICAS - IBGE. Censo Agropecuário 2006. Rio de Janeiro: IBGE, 2007

KRUGMAN, P. Geography and trade. Cambridge: MIT, 1991.

MARION FILHO, P. J. et al. Concentração regional e especialização na produção de leite do Rio Grande do Sul (1990-2010). Revista Brasileira de Gestão e Desenvolvimento Regional, v. 11, n. 1, 2015.

MARION FILHO, P. J.; OLIVEIRA, L. F. V. de. A especialização e a concentração da produção de leite nas microrregiões do Rio Grande do Sul (1990 - 2007). Ensaios FEE, Porto Alegre, v. 31, Número Especial, p. 635- 647, jun. 2011.

MEDAUAR, O. Direito administrativo concreto. São Paulo: Revista dos Tribunais, 2001.

RIO, C. T. Análise do modelo de gestão da Agência Paulista de Tecnologia dos Agronegócios (APTA). 2009. Dissertação (Mestrado) - Instituto de Geociências, Universidade Estadual de Campinas, Campinas: Unicamp, 2009, p. 47-50; 65-72.

SALLES FILHO, S.. et al. CT\&I no setor agrícola no Estado de São Paulo. In: BRENTANI, R. R.; BRITO CRUZ, C. H. (Orgs.). Indicadores de ciência, tecnologia e inovação em São Paulo 2010. São Paulo: FAPESP, 2011.

SALLES FILHO, S.; BONACELLI, M. B.; MELLO, D. Metodologia para o estudo da reorganização institucional da pesquisa pública. Parcerias Estratégicas, Brasília, n. 9, p. 43, 2000.

SÃO PAULO (Estado). Decreto n. 46.488, de 08 de janeiro de 2002. Reorganiza a Agência Paulista de Tecnologia dos Agronegócios (APTA), da Secretaria de Agricultura e Abastecimento, e dá providências correlatas. Diário Oficial do Estado de São Paulo, 09 jan. 2002.

SÃO PAULO (Estado). Secretaria de Agricultura e Abastecimento. Coordenadoria de Assistência Técnica Integral. Instituto de Economia Agrícola. Levantamento censitário das unidades de produção agropecuária do Estado de São Paulo - Projeto LUPA 2007/08. São Paulo: SAA/CATI/IEA, mar. 2009.

SICSÚ, A.B.; DA SILVEIRA, S.K. Construção de programas de gestão estratégica para Organizações Estaduais de Pesquisa Agropecuária no Brasil: aspectos metodológicos. Navus-Revista de Gestão e Tecnologia, v. 3, n. 1, p. 36-48, 2013.

STATSOFT, Inc. STATISTICA (data analysis software system), version 8.0. Tulsa, OK. 1997. Disponível em: <www.statsoft.com>.

SUZIGAN, W; FURTADO, J.; GARCIA, R.; SAMPAIO, S. E. K. Coeficientes de Gini locacionais - GL: aplicação à indústria de calçados do Estado de São Paulo. Nova Economia, Belo Horizonte, p. 39-60, jul.- dez. 2003.

SUZIGAN, Wilson et al. Cluster e Sistemas Locais de Produção: Mapeamento, Tipologia e Sugestões Políticas. Revista de Economia Política, v. 24, n.04, 2004.

TSUNESHIRO, A. et al.. Valor da Produção Agropecuária do Estado de São Paulo em 2013. Análises e Indicadores do Agronegócio. IEA, v9, n.04, 2014. 
VICENTE, J.R. Balança Comercial dos Agronegócios Paulista e Brasileiro no Ano de 2013.

Disponível em: http://www.iea.sp.gov.br/out/TerTexto.php?codTexto=12851. Acesso em 20 de nov. 2014. 